\title{
REPRESENTAÇÕES SOCIAIS DE ESTUDANTES DE CIÊNCIAS CONTÁBEIS SOBRE A DISCIPLINA DE TEORIA DA CONTABILIDADE
}

http://dx.doi.org/10.5902/2318133844606

\author{
Valdecir de Sousa Salgueiro Filho ${ }^{1}$ \\ Pablo Francisco Sousa Carvalho ${ }^{2}$ \\ Isael Mendes de Sousa ${ }^{3}$ \\ Cleber Augusto Pereira ${ }^{4}$
}

\section{Resumo}

O objetivo deste trabalho foi identificar e analisar as representações sociais acerca da Teoria da Contabilidade por estudantes do curso de Ciências Contábeis da UFMA. A pesquisa ocorreu em 2019, em duas fases, e foi aplicada a 76 estudantes. Utilizou-se a técnica de associação livre de palavras por meio do seguinte estímulo indutor: quais as cinco primeiras palavras que lhe veem a mente ao ouvir o termo Teoria da Contabilidade? Na interpretação dos dados foi adotada a teoria das representações sociais e o tratamento das respostas utilizou a matriz de análise prototípica. As evocações dos estudantes mostram que a visão final, quando comparada à inicial, evidenciou a absorção dos conceitos ao evocarem os termos postulado, estrutura conceitual e convenção contábil, não evocados na fase inicial.

Palavras-chave: teoria da contabilidade; representação social; análise prototípica; Talp; percepção dos estudantes.

\section{SOCIAL REPRESENTATIONS OF ACCOUNTING SCIENCES STUDENTS ON ACCOUNTING THEORY DISCIPLINE}

\begin{abstract}
The objective was to identify and analyze the social representations on Accounting Theory by students. Research carried out in 2019, in two phases, and applied to 76 students of the Bachelor of Science course in Accounting. The Free Word Association Technique was used through the inducing stimulus: "What are the first five words that come to mind when you hear the term Accounting Theory?" In the interpretation of the data, the theory of social representations was adopted. The treatment of responses used the prototypical analysis matrix. The evocations of the students show that the final vision, when compared to the initial one, evidenced the absorption of the concepts when evoking the terms postulated, conceptual structure, and accounting convention, not evoked in the initial phase.
\end{abstract}

Key-words: accounting theory; social representation; prototypical analysis; Talp; perception of students.

\footnotetext{
${ }^{1}$ Escola Municipal Tomé de Sousa de Imperatriz, Brasil. E-mail: filhosalqueiro@gmail.com.

2 Universidade Federal do Maranhão, Brasil. E-mail: pablofsc97@gmail.com.

3 Universidade Federal do Maranhão, Brasil. E-mail: isaelmd@gmail.com.

4 Universidade Federal do Maranhão, Brasil. E-mail: kcleber@gmail.com.
Santa Maria
v. 9
n. 18
Pub. contínua 2020
p. 1-16

Regae: Rev. Gest. Aval. Educ.
} 


\section{Introdução}

contabilidade está num momento de transição: seu ambiente passou por
diversas mudanças nas últimas décadas e um ritmo acelerado de mudanças
ainda está na perspectiva para o futuro, principalmente com a tecnologia. Diante destas mudanças é importante a compreensão da contabilidade como forma de conhecimento, o que pode ocorrer pelo estudo de várias áreas da contabilidade, como a história, os princípios contábeis e da teoria da contabilidade (Borba; Poeta; Vicente, 2011).

Obrigatória nos cursos de graduação em Ciências Contábeis a partir da resolução n. 3, do Conselho Federal de Educação, de 5 de outubro de 1992 (CFE, 1992), a disciplina de Teoria da Contabilidade visa, conforme esta resolução, a estimular a aquisição integrada de conhecimentos teóricos e práticos que permitam o competente exercício da profissão.

Borba, Poeta e Vicente (2011) declaram que a adesão brasileira às normas internacionais de contabilidade gerou um aumento na subjetividade e a ênfase nas características qualitativas da informação contábil. Para isto, torna-se necessário que os profissionais tenham uma base teórica para resolver problemas inéditos e complexos, que não estejam previstos em normas o que, de certo modo, eleva a responsabilidade e o reconhecimento da profissão perante a sociedade. Com isso, é importante observar que o professor é o principal mediador nos processos de ensino e aprendizagem dos estudantes, utilizando de todo seu arcabouço teórico para qualificação dos discentes (Silva et al., 2019).

Ademais, concernente à disciplina de Teoria da Contabilidade, ressalta-se que este componente curricular pode oferecer uma contribuição singular com relação ao esforço de promover na ciência contábil uma reflexão subjetiva, fornecendo explicações racionais e contextualizadas sobre os principais fenômenos contábeis existentes atualmente (Buchweitz et al., 2019).

Diante disso, o objetivo desta pesquisa foi responder a seguinte pergunta: qual foi a evolução da percepção dos estudantes do curso de Ciências Contábeis sobre a disciplina Teoria da Contabilidade entre o início e o término da disciplina? A pesquisa foi realizada durante o segundo semestre de 2019, em duas fases, com os estudantes do bacharelado em Ciências Contábeis da Universidade Federal do Maranhão.

\section{Teoria da contabilidade}

A Teoria da Contabilidade oferece uma compreensão melhor das práticas existentes para contadores, administradores, investidores e estudantes, oferece um referencial conceitual para a avaliação de práticas contábeis existentes e orienta o desenvolvimento de novas práticas e novos procedimentos (ludícibus; Beuren; Santos, 2016). Contudo, ela recebe influências de várias outras disciplinas e vem reinventando-se continuamente nas últimas décadas, que vai do surgimento e ampla disseminação da abordagem positiva, com suas técnicas quantitativas e embasamento econômico, à ascensão da escola inglesa, com viés sociológico e densos estudos históricos (ludícibus; Marion; Faria, 2009).

ludícibus, Beuren e Santos (2016) mencionam que a própria Teoria da Contabilidade pode ser classificada de diversas maneiras: por nível: sintático, semântico ou pragmático; por tipo de raciocínio: dedutivo, indutivo; por atitude: normativa, positiva. 
Os autores elucidam que cada enfoque para a definição da Teoria da Contabilidade requer um método distinto de verificação. Iudícibus, Marion e Faria (2009) chamam a atenção para um aspecto que deve ser definitivamente superado, que é o falso dilema positivismo versus normativismo. Segundo ludícibus, Marion e Faria (2009) "a teoria da contabilidade é um conjunto articulado de postulados, princípios e restrições. As pesquisas, de qualquer tipo, irão, aos poucos, enriquecendo esse conjunto com a evidência das provas, ou seja, a teoria confirmada pelas pesquisas empíricas" (p. 11).

Como disciplina em cursos superiores ela possui um histórico bastante recente, quando comparada, por exemplo, à economia. Os primeiros livros de teoria contábil datam do final do século 19, enquanto os de economia já eram conhecidos desde o século 15. A contabilidade demorou a pensar-se como teoria, em pesquisas e metodologias científicas (ludícibus, 2012).

No Brasil, a primeira escola especializada no ensino da contabilidade foi a Escola de Comércio Armando Álvares Penteado, criada em 1902, com os ensinamentos voltados à escola italiana. No entanto, os primeiros artigos científicos surgiram no Departamento de Ciências Contábeis e Atuariais da Faculdade de Economia, Administração e Contabilidade da Universidade de São Paulo a partir do pensamento contábil norte-americano (Sacramento, 1998).

Com a resolução n. 003, de 05/10/1992, do Conselho Federal de Educação, a obrigatoriedade da disciplina de Teoria da Contabilidade no currículo dos cursos de graduação em Ciências Contábeis no Brasil entrou em vigor. Ela se tornou necessária para que os estudantes tenham uma base conceitual de qualidade, atendendo às necessidades do mercado, pois é por meio de metodologias científicas que é possível explicar a realidade (Madeira; Mendonça; Abreu, 2003).

A disciplina Teoria da Contabilidade contribui para a formação do profissional contábil, pois ela proporciona o entendimento das normas e princípios fundamentais da contabilidade, dos seus conceitos e objetivos, abordando o pensamento contábil e promovendo a compreensão das teorias que a fundamentam (Madeira; Mendonça; Abreu, 2003).

\section{Princípios de Contabilidade versus estrutura conceitual}

Conforme a resolução n. 1.121 do Conselho Federal de Contabilidade, de 28 de março de 2008 (CFC, 2008), a contabilidade, na sua condição de ciência social, cujo objeto é o patrimônio, busca, por meio da apreensão, da quantificação, da classificação, do registro, da eventual sumarização, da demonstração, da análise e relato das mutações sofridas pelo patrimônio da entidade particularizada, a geração de informações quantitativas e qualitativas sobre ela, expressas tanto em termos físicos, quanto monetários.

Nesses termos a contabilidade tem como seu objeto o patrimônio e, para atingir suas finalidades, desenvolve suas funções ao redor dele. (Franco, 1995). O objeto delimita o campo de abrangência desta ciência, que na contabilidade é definido pelo conjunto de bens, direitos e obrigações para com terceiros, pertencendo a uma pessoa física ou jurídica (ludícibus; Martins; Gelbcke, 2000).

Os princípios fundamentais da contabilidade são o ponto de partida para a compreensão da própria Ciência Contábil, pois são eles que fundamentam os conceitos, a teoria e a prática desta ciência (ludícibus; Martins; Gelbcke, 2000). Até 2016 os princípios con- 
tábeis eram ditados pela resolução n. 750/93, sendo substituída pela Norma Brasileira de Contabilidade - NBC TG Estrutura Conceitual. Na resolução n. 750/93 os princípios eram elencados no capítulo 2. Nesta existiam sete princípios: entidade, continuidade, oportunidade, registro pelo valor original, atualização monetária, competência e prudência.

$\mathrm{Na}$ estrutura conceitual o princípio da atualização monetária foi revogado pela resolução CFC n. 11282/10, existindo então, seis princípios. Diferente da resolução n. 750/93, a estrutura conceitual não elenca os princípios contábeis. Contudo eles foram absorvidos pelos CPC's, necessitando de muita atenção para identificá-los. Vale ressaltar que os princípios não mudaram, pois continuaram com sua essência.

Para Paganotto, Rossoni e Filho (2008) o profissional contábil deve considerar a qualidade da informação prestada como a ferramenta mais importante na prestação do serviço, até mesmo como forma de se manter no mercado que é cada vez mais competitivo em todas as áreas, especialmente na área contábil. Para que o profissional contábil atinja o nível de competência necessária para prestar as informações de qualidade em atendimento aos anseios dos usuários, não se pode esquecer-se da necessidade de busca de novos conhecimentos, o que será tratado no item a seguir.

\section{Teoria das representações sociais}

A Teoria das Representações Sociais - TRS - se iniciou na metade do século 20, foi desenvolvida na França por Serge Moscovici, com intuito de descobrir ou entender mais sobre a Psicanálise (Silva; Camargo; Padilha, 2011). A TRS tem por objetivo estudar reuniões de informações que viabilizam uma compreensão no que diz respeito às representações decorrentes da interação social. A Representação Social - RS - é uma modalidade de aprendizado particular que tem por objetivo a construção de comportamentos e a comunicação entre sujeitos (Moscovicl, 1978). Contudo, nenhuma técnica por si só conseguirá revelar todas as evidências de que necessitamos para compreendermos a realidade numa clara constatação de que múltiplas técnicas e perspectivas, até mesmo antagônicas, podem se coadunar a fim de gerar os resultados esperados.

\section{Técnica de Associação Livre de Palavras - Talp}

A Talp é uma ferramenta do tipo projetiva, pois utiliza dados verbais e não verbais para coleta de dados e, por meio disso, consegue capturar os aspectos, personalidade e os fatores dos indivíduos acerca do objeto indutor, como menciona (Tavares et al., 2014). Inicialmente, a Talp, como técnica projetiva, provoca a amostra da pesquisa Ihe falando um termo e pedindo que através deste termo o pesquisado evoque as cinco primeiras palavras que vem a sua mente. Pelos estudos de Coutinho e Bú (2017) a técnica Talp é evidenciada sobre quatros classes de uma avaliação projetiva: despertar, observar, armazenar e conseguir a comunicação verbal.

\section{A técnica de associação livre de palavras e a análise prototípica}

A análise prototípica é um dos principais métodos que busca analisar ou tratar as representações sociais (Wachelke; Wolter; Matos, 2016). Nela são expostos quatro quadrantes, cada um com uma função diferente. 
Para a classificação das palavras que ficam nos quadrantes são utilizados dois métodos: a Ordem Média de Evocação - OME - e a frequência das palavras. A frequência das palavras é a quantidade de vezes em que um termo foi evocado pela amostra. Para se chegar a OME, segundo Correia e Joia (2014), utiliza-se a equação 1:

$$
\mathrm{OME}=\frac{(f 1 * 1)+(f 2 * 2)+(f 3 * 3)+(f 4 * 4)+(f 5 * 5)}{\Sigma f}
$$

Em que $f 1, f 2, f 3, f 4$ e $f 5$ representam os termos que foram evocados em primeiro, segundo, terceiro, quarto e quinto lugar, respectivamente, e pela equação são multiplicados pelos seus respectivos pesos atribuídos para cada posição.

O Núcleo Central é o mais importante dos quatro quadrantes: nele são exibidas as palavras que formam a Representação Social, com isso geralmente ela tem as palavras com maior número de evocação e uma OME abaixo da média (Wachelke; Wolter; Matos, 2016).

Em seguida há a Primeira Periferia, com os termos que dão sustentação para as convicções do Núcleo Central (Santos et al., 2019). Ainda na primeira periferia estão os termos com alta frequência e alta OME. A Segunda Periferia tem palavras com baixa frequência e alta OME. Já na Zona de Contraste estão expostas as palavras com baixa frequência e baixa OME (Santos et al., 2019).

\section{Teoria do núcleo central}

A Teoria do Núcleo Central é um arcabouço hierarquizado composto por elementos centrais e periféricos. Esses elementos são compostos por um conjunto de informações, crenças e atitudes. Com isso os elementos periféricos ficam em torno do Núcleo Central dando apoio e edificando análise interna da RS (Abric, 2001).

O Núcleo Central é o principal dos elementos e mostra os termos que fazem parte da RS da análise, representando a importância do grupo, compondo o centro das representações geradas pela situação e pelos atributos particulares de cada amostra (Amaral; Alves, 2013).

\section{Metodologia}

Este estudo foi realizado no ano de 2019, entre os meses de agosto e dezembro. Foi aplicada aos 40 estudantes do terceiro período da disciplina de Teoria da Contabilidade do curso de Ciências Contábeis da Universidade Federal do Maranhão. Foram feitos dois Talps: um no primeiro dia de aula, antes de iniciar a apresentação do conteúdo programático, e outro no último encontro da disciplina, para avaliar a evolução dos estudantes.

No primeiro momento foi feita a Talp no Google forms com o estimulo indutor 'quais as cinco primeiras palavras que veem a sua mente quando escuta o termo 'Teoria da Contabilidade?'. Tal formulário obteve 40 respostas válidas, sendo 22 respostas de indivíduos do sexo masculino e 18 do sexo feminino. 
No segundo momento, encerramento da disciplina, foi aplicada novamente a Talp com o mesmo estímulo indutor, só que sua resposta foi realizada pelos estudantes concluintes da disciplina, utilizando um papel individual para cada aluno. Obteve-se trinta e seis respostas válidas: 22 respostas de estudantes do sexo masculino e 14 do sexo feminino.

As respostas coletadas pelas Talp foram digitadas em planilhas eletrônicas do programa Excel, para depois serem tratadas no software, através da Análise Prototípica. Foi escolhida a Teoria das Representações Sociais com o objetivo de compreender os fatos que envolvem a relação entre os seres humanos e explicar as RS dos estudantes. Utilizamos os elementos da TRS como base referencial para o tratamento dos dados, destacando-se a Teoria do Núcleo Central e a Primeira Periferia. Utilizamos como gerenciador bibliográfico o software Mendeley desktop que, de acordo com Yamakawa et al. (2014) serve para administrar e inserir citações de forma simples em arquivos de texto.

\section{Resultados}

Para chegar aos resultados foi usada a Talp e a Análise Prototípica com o objetivo de identificar e tratar os dados necessários para o presente estudo. Esta seção foi dividida em duas fases: a primeira análise avaliou a expectativa dos estudantes sobre a disciplina de Teoria da Contabilidade antes desta iniciar; a segunda análise foi verificativa da percepção final dos estudantes, tendo sido aplicada ao encerramento da disciplina.

Embora tenhamos utilizado o mesmo termo indutor nas duas fases, a forma de aplicação foi distinta. O primeiro questionário foi coletado de forma eletrônica, tendo o link de acesso sido disponibilizado aos estudantes por meio eletrônico e as respostas foram preenchidas e enviadas pelos smartphones dos estudantes. No segundo questionário, após a realização da avaliação final da disciplina, os estudantes foram convidados a responder a mesma pergunta, só que neste momento, utilizando caneta e papel.

Há diferenças na aplicação, pois a primeira foi eletrônica e mediada por tecnologia, sendo que os respondentes, a dela participarem, tiveram acesso a recursos de auto completar e do dicionário instalado nos dispositivos eletrônicos. Já na segunda interação espera-se ter forçado a reflexão dos respondentes sobre o aprendizado por estes retido, o fato de utilizar uma folha e papel também evitaram qualquer facilitação ou indução de termos a serem utilizados nas respostas.

\section{Análise da primeira fase da pesquisa - expectativa dos estudantes sobre a disciplina}

Para que os estudantes não sofressem nenhuma influência que possibilitasse qualquer tipo de inclinação concernente às respostas, nada Ihes foi dito acerca da natureza da disciplina até que todos tivessem fornecido os termos sugeridos. 
Tabela 1 -

Primeira fase da pesquisa: análise prototípica das evocações dos discentes.

\begin{tabular}{|c|c|c|c|c|c|c|}
\hline \multirow{10}{*}{ 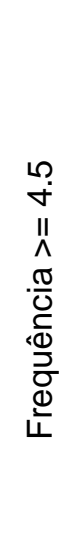 } & \multicolumn{3}{|c|}{ Ord. méd. de evoc $<=2.83$} & \multicolumn{3}{|c|}{ Ord. méd. de evoc $>2.83$} \\
\hline & \multicolumn{3}{|c|}{ Núcleo central } & \multicolumn{3}{|c|}{ Primeira periferia } \\
\hline & Palavra & Frequência & OME & Palavra & Frequência & OME \\
\hline & História & 23 & 2.1 & Início & 9 & 2.9 \\
\hline & Conceito & 9 & 2 & Estudo & 7 & 3.7 \\
\hline & Teoria & 9 & 1.6 & Base & 5 & 3.2 \\
\hline & Princípio & 9 & 2.2 & Ciência & 5 & 3.4 \\
\hline & Fundamento & 7 & 2.4 & & & \\
\hline & Técnica & 5 & 2.4 & & & \\
\hline & Evolução & 5 & 2.4 & & & \\
\hline \multirow{18}{*}{ 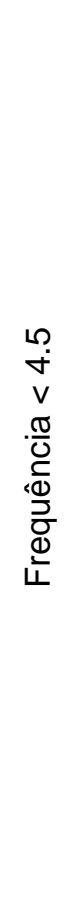 } & \multicolumn{3}{|c|}{ Zona de contraste } & \multicolumn{3}{|c|}{ Segunda periferia } \\
\hline & Palavra & Frequência & OME & Palavra & Frequência & OME \\
\hline & Ensino & 2 & 2.5 & Contabilidade & 3 & 4 \\
\hline & Pesquisa & 2 & 1.5 & Leitura & 3 & 3.3 \\
\hline & Texto & 2 & 2 & Método & 3 & 4.3 \\
\hline & & & & Origem & 3 & 3 \\
\hline & & & & Aplicação & 2 & 4.5 \\
\hline & & & & Metodologia & 2 & 4 \\
\hline & & & & Cálculo & 2 & 4 \\
\hline & & & & Essência & 2 & 4 \\
\hline & & & & Conhecimento & 2 & 4 \\
\hline & & & & Autor & 2 & 5 \\
\hline & & & & Aprendizado & 2 & 4.5 \\
\hline & & & & Análise & 2 & 3.5 \\
\hline & & & & Objetivo & 2 & 3.5 \\
\hline & & & & Ativo & 2 & 4.5 \\
\hline & & & & Desenvolvimento & 2 & 5 \\
\hline & & & & Convenção & 2 & 3 \\
\hline
\end{tabular}

Fonte: Elaboração própria.

$\mathrm{Na}$ tabela 1 mostra-se a matriz prototípica da primeira fase da pesquisa, as informações serviram para identificar as percepções iniciais dos estudantes quanto ao tema proposto. Para Teixeira (2014), a análise de dados consiste em etapa indispensável no processo de construção do conhecimento. É neste momento que o pesquisador se depara com as informações que devidamente trabalhadas se transformarão em conhecimento.

Exemplifica-se na equação 2 como foi calculada a OME com a palavra 'história'. Em $f 1$ a palavra 'história' se repetiu sete vezes, f2 se repetiu nove vezes, f3 se repetiu quatro vezes, $f 4$ se repetiu três vezes e $f 5$ a palavra não se repetiu. De acordo esses dados plotou-se a equação que calculou o valor da OME de '2,1' do termo 'história':

$$
\frac{\left(7^{\star} 1\right)+\left(9^{\star} 2\right)+\left(4^{\star} 3\right)+\left(3^{\star} 4\right)+\left(0^{\star} 5\right)}{23}=2.1304
$$




\section{Análise das evocações no Núcleo Central}

O Núcleo central, superior esquerdo, contém os elementos de alta frequência e baixa OME. Ao analisarmos o primeiro quadrante obtido a partir das evocações de palavras dos estudantes ingressantes na disciplina de Teoria da Contabilidade, identificouse que a palavra com a maior ordem de evocação foi 'história', $f=23$ e OME=2,1.

Com base nesta primeira premissa pode-se inferir que, mesmo de forma incipiente, é notório que os estudantes ingressantes da disciplina conseguiram relacionar de forma satisfatória a Teoria da contabilidade como sendo um ramo desta ciência que se dedica ao estudo do aspecto histórico da contabilidade.

A segunda palavra que se destaca é 'conceito', $f=9$ e $O M E=2$ que, junto com as palavras 'teoria', $f=9$ e $O M E=1,6$ e 'princípio, $f=9$ e $O M E=2,2$, aparecem de forma um pouco semelhante no quesito evocação do termo, fortalecendo a visão do grupo no que tange a noção de Teoria da Contabilidade.

Após o termo 'conceito' ter sido evocada nove vezes e, aparecendo na segunda colocação do Núcleo Central, presume-se que a relação construída pelos estudantes concebe ou entende que a Teoria da Contabilidade de alguma forma trataria de elementos conceituais da contabilidade, tais como, definição, exposição ou esclarecimento, no que tange a disciplina. Com a mesma frequência aparece o termo 'teoria'. Acredita-se que ao evocar esta palavra os estudantes imaginavam que a disciplina versaria sobre 0 arcabouço teórico metodológico, demonstrando como se deu o processo de sistematização da contabilidade.

Entende-se que dos termos evocados pelos participantes ingressantes na disciplina a palavra 'técnica', $f=5$ e $O M E=2,4$ seria a única que destoa dos demais termos, evidenciando que o grupo possui uma boa percepção do que seria a disciplina, esta percepção ainda não está completamente consolidada, motivo pelo qual o termo surge e desaparece de forma abrupta no segundo momento do Talp.

\section{Análise das evocações na Primeira Periferia}

A primeira periferia, superior direito, contém os elementos com alta frequência e OME mediana. Sustentando este argumento Santos et al (2019) informam que a Primeira Periferia mostra os termos que dão força e sustentam os conceitos encontrados no Núcleo Central, as palavras que estão neste quadrante têm uma alta frequência e uma OME mediana.

A palavra mais citada na Primeira Periferia foi 'início', $f=9$ e $O M E=2,9$. Para a amostra pesquisada essa palavra remete o início da contabilidade e, pelo nome da disciplina ser Teoria da Contabilidade, muitos participantes da pesquisa evocaram esse termo por pensar que o assunto abordado pelo professor na disciplina seria a história do começo da contabilidade, nota-se que a palavra 'início' serve de base para as palavras 'história' e 'teoria' que estão alocadas no Núcleo Central.

A segunda palavra mais evocada foi 'estudo', $f=7$ e $O M E=3,7$. Essa palavra aparece por essa disciplina ser específica do curso de Contabilidade e por isso deve existir um esforço maior por parte dos estudantes. As outras palavras evocadas foram 'base', $f=5$ e $\mathrm{OME}=3,2$, e 'ciência', $f=5$ e $\mathrm{OME}=3,4$. Com base na Representação Social e na Primeira Periferia vimos que os estudantes tinham uma breve noção do que era Teoria da Contabilidade. 


\section{Análise das evocações na Segunda Periferia}

A Segunda periferia, inferior direito, mostra os termos com baixa frequência e alta OME. De acordo com Wachelke e Wolter (2011) a Segunda periferia tem frequência inferior ao ponto de corte da análise e os termos que fazem parte deste quadrante são evocados como últimas respostas.

Ao observarmos a matriz, mais especificadamente a Segunda periferia, percebe-se que a maior parte dos elementos se encontra neste quadrante. Contudo, isto não significa muita coisa visto que existe uma flexibilidade de ideias e pensamentos discrepantes tornando tais termos sem força para alimentar a análise.

As palavras mais citadas foram 'contabilidade', $f=3$ e $O M E=4$, 'leitura', $f=3$ e $\mathrm{OME}=3,3$, 'método', $f=3$ e $\mathrm{OME}=4,3$ e 'origem', $f=3$ e $\mathrm{OME}=3$. A palavra 'contabilidade' entrou nesta análise porque faz referencia a matéria, ou seja, tem que ter contabilidade quando se falar em uma matéria específica de contabilidade. Quando a palavra 'leitura' é evocada infere-se que na concepção dos estudantes no decorrer da disciplina muito se leria sobre a matéria ministrada no semestre.

\section{Análise das evocações na Zona de Contraste}

As palavras da Zona de Contraste, inferior esquerdo, são palavras pouco citadas e que foram evocadas cedo pela amostra: nesta periferia tanto a frequência como a OME das palavras são baixas (Wachelke; Wolter, 2011).

Dentre os quatro quadrantes o mais desvalorizado é a Zona de Contraste por causa de sua frequência e sua OME baixa. As palavras que fazem parte deste quadrante deveriam estar distribuídas nos outros quadrantes, pois as palavras inseridas neles são extremamente importantes quanto às outras palavras dos demais quadrantes.

Os termos deste quadrante são 'ensino', $f=2$ e $O M E=2,5$, 'pesquisa', $f=2$ e $O M E=1,5$ e 'texto', $f=2$ e $O M E=2$ : todos com a mesma frequência e com OME diferente, nota-se que 'ensino' e 'pesquisa' são palavras muito relevantes e que deveriam estar ou no Núcleo Central ou nas periferias, observou-se também que neste quadrante 0 aluno já diagnostica que devem ser priorizados, tanto o ensino, quanto para a pesquisa, pois de acordo com Cunha et al. (2017), a matéria só foi inserida no ensino da Contabilidade no ano de 1994 e por isso existem poucas literaturas sobre o assunto.

\section{Análise da segunda fase da pesquisa - resultados de aprendizagem dos estudantes na disciplina}

Nesta fase os estudantes já haviam tido contato com o conhecimento teórico da disciplina, contudo, desconheciam a natureza da pesquisa a que estavam sendo submetidos, estando, neste sentido, isentos de influências quanto aos objetivos do pesquisador.

$\mathrm{Na}$ tabela 2 apresenta-se a matriz prototípica com as evocações desta fase do estudo: percebe-se que rapidamente a contato com a nova estrutura conceitual produziu importante incremento nos conhecimentos teóricos dos estudantes, prova disto sendo o aparecimento dos termos 'postulado' e 'estrutura' nesta fase da pesquisa. 
Tabela 2 -

Segunda fase - análise prototípica das evocações dos discentes.

\begin{tabular}{|c|c|c|c|c|c|c|}
\hline \multirow{8}{*}{ 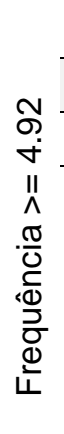 } & \multirow{2}{*}{\multicolumn{3}{|c|}{$\begin{array}{c}\text { Ord. méd. de evoc }<=2.79 \\
\text { Núcleo central }\end{array}$}} & \multicolumn{3}{|c|}{ Ord. méd. de evoc $>2.79$} \\
\hline & & & & \multicolumn{3}{|c|}{ Primeira periferia } \\
\hline & Palavra & Frequência & OME & Palavra & Frequência & OME \\
\hline & Postulado & 10 & 2.1 & Princípio & 21 & 2.9 \\
\hline & Conceito & 10 & 2.3 & Norma & 11 & 3.3 \\
\hline & História & 8 & 2.6 & Base & 8 & 3.2 \\
\hline & Estrutura & 6 & 1.8 & Convenção & 5 & 2.8 \\
\hline & Teoria & 5 & 2.2 & & & \\
\hline \multirow{13}{*}{ 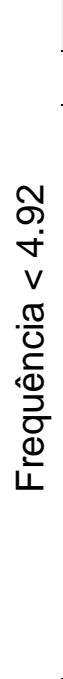 } & \multicolumn{3}{|c|}{ Zona de contraste } & \multicolumn{3}{|c|}{ Segunda periferia } \\
\hline & Palavra & Frequência & OME & Palavra & Frequência & OME \\
\hline & Fundamento & 3 & 2.7 & Informação & 4 & 2.8 \\
\hline & Conhecimento & 3 & 1.3 & Fundamentação & 3 & 3 \\
\hline & Patrimônio & 2 & 2 & Essência & 3 & 4.3 \\
\hline & Distorção & 2 & 2.5 & Leitura & 3 & 3.7 \\
\hline & Alicerce & 2 & 2.5 & Entidade & 2 & 3 \\
\hline & & & & Evolução & 2 & 5 \\
\hline & & & & Ativo & 2 & 3 \\
\hline & & & & Pesquisa & 2 & 3.5 \\
\hline & & & & Fato & 2 & 3 \\
\hline & & & & Estudo & 2 & 3 \\
\hline & & & & Continuidade & 2 & 4 \\
\hline
\end{tabular}

Fonte: Elaboração própria.

\section{Análise das evocações no Núcleo Central}

No segundo momento da pesquisa em que os estudantes foram novamente indagados sobre as mesmas questões relativas à disciplina de Teoria da Contabilidade, os termos que compuseram o Núcleo Central da matriz foram os seguintes: 'postulado', $f=10$ e $\mathrm{OME}=2,1$; 'conceito', $f=10$ e $\mathrm{OME}=2,3$; 'história', $f=8$ e $\mathrm{OME}=2,6$; 'estrutura', $f=6$ e $\mathrm{OME}=1,8$; e 'teoria' $f=5$ e $\mathrm{OME}=2,2$.

O termo 'postulado' está alinhado ao que a ementa da disciplina de Teoria da Contabilidade se propõe a ofertar. Entende-se que o fato de o termo ter aparecido apenas neste segundo momento da pesquisa, mesmo sendo um termo muito importante' reflete o fato de que os estudantes naquele primeiro momento desconheciam com profundidade os elementos centrais da disciplina.

O termo 'conceito' permanece como segunda palavra mais evocada do Núcleo Central sem muitas alterações. Por outro lado, o termo 'história' que havia sido evocado diversas vezes no primeiro momento e se estabelecido no Núcleo Central, agora aparece na terceira colocação com respeito ao Núcleo Central. Tal constatação não significa que o termo tenha perdido a importância, mas que outras palavras mais adequadas tenham emergido e foram conduzidas para o Núcleo Central. 


\section{Análise das evocações na Primeira Periferia}

$\mathrm{Na}$ Primeira periferia ao depararmos com o termo 'princípio', $f=21$ e OME=2,9, podese indagar o porquê deste termo não está representado no quadrante alusivo ao Núcleo Central. Como explicado na análise da primeira matriz prototípica, especificadamente no primeiro quadrante-núcleo central, para que um termo seja representado neste é preciso que ele siga algumas condicionantes, tais como: apresentar uma frequência alta, ou seja, alta ordem de evocação e baixa OME.

Por outro lado, para que um termo se destaque na Primeira Periferia se torna necessário que, além de possuir alta frequência, também possua alta OME, fato que ocorre com o termo 'princípio' de forma clara e inequívoca.

O termo 'norma', $f=11$ e $O M E=3,3$, segue o mesmo raciocínio do termo 'princípio'. Está na Primeira Periferia porque tem alta frequência e alta OME. O termo 'norma', para a amostra pesquisada, refere-se às Normas Brasileiras de Contabilidadeque, de acordo com CFC (2008), é um conjunto de regras e procedimentos que devem ser considerados para o exercício da profissão contábil.

Em seguida temos o termo 'base', $f=8$ e $O M E=3,2$, que se encontra estreitamente relacionado aos termos do Núcleo Central, que se não fosse a OME alta estaria sem sombras de dúvidas disputando um espaço com os termos do Núcleo Central visto que aparecem com alta frequência.

\section{Análise das evocações na Segunda Periferia}

A Segunda Periferia não agrega muito quanto ao que os estudos geralmente se propõem a demonstrar que, via de regra, em se tratando em Representações Sociais, seria evidenciar os pontos centrais que tornam os indivíduos homogêneos com respeito a um tema qualquer. Contudo, cabe ressaltar que é neste quadrante onde mais termos diferentes são citados, porém, os termos que apresentam baixa frequência e alta OME, podendo, assim, ser entendido como um setor em que existe certa dispersão cognitiva dos envolvidos com respeito ao tema.

Neste quadrante além dos termos serem citados poucas vezes pelos entrevistados, às vezes em que o foram, acontecem numa ordem média alta evidenciando que tais termos não seguem acompanhados de tanta importância. Dos onze termos mencionados poderíamos tecer alguns comentários sobre aqueles que poderiam representar um pensamento consistente acerca do que a disciplina representaria para os estudantes, tais como 'essência' e 'leitura'.

'Essência', $f=3$ e $O M E=4,3$, diz respeito à natureza intrínseca de algo, aquilo sem o qual não seria tal qual. Por este motivo acredita-se que os poucos indivíduos que evocaram este termo imaginaram que a essência da Ciência Contábil seria esboçado na disciplina. O segundo termo que se considera relevante é 'leitura', $f=3$ e $O M E=3,7$, por se imaginar que, por ser tarefa indispensável ao acadêmico, proporciona que tomemos conhecimento de todos os eventos relevantes no campo acadêmico por meio dela. Acredita-se que a relação do termo no imaginário dos estudantes favorece ideia de que durante a disciplina muita teoria ser-lhes-ia apresentada.

Um termo que, inesperadamente, surgiu neste quadrante é 'ativo': $f=2$ e $O M E=3$. Não é possível estabelecer com clareza a relação que os estudantes fizeram ao evocar tal termo, visto que o termo ativo geralmente surge em disciplinas um tanto práticas e nas 
quais não se requer muita relação com elementos eminentemente teóricos. Contudo, a evocação do termo de alguma forma transparece que certos indivíduos conseguem relacionar a natureza teórica da disciplina com a natureza prática da Ciência Contábil, 0 que é muito importante, visto que teoria e prática são inseparáveis.

\section{Análise das evocações na Zona de Contraste}

$\mathrm{Na} Z$ Zona de contraste as palavras mais citadas foram 'fundamento', $f=3$ e OME=2,7, 'conhecimento', $f=3$ e $\mathrm{OME}=1,3$ e 'patrimônio', $f=2$ e $\mathrm{OME}=2$. É importante salientar que nenhuma palavra das duas análises da Zona de Contraste se repetiu, e por isso foi verificado que muitos conceitos iniciais da análise não permaneceram na pesquisa, evidenciando que o grupo amostral, depois de ter concluído a disciplina, mudou sua percepção.

A palavra 'fundamento', mais evocada pelo grupo amostral, significa base da disciplina, ou seja, estrutura que a sustenta, sejam os princípios, postulados entre outros assuntos abordados pela disciplina fundamentais para sua manutenção.

A segunda palavra mais citada pela amostra foi 'conhecimento' e significa para o grupo pesquisado informação ou conhecimento que pode ser entendido pelos assuntos ministrados na disciplina.

A terceira palavra que se destacou neste quadrante foi 'patrimônio': ela está relacionada aos termos que são usados na disciplina, mas também pode ser entendida como o objeto de estudo da Contabilidade, com isso corre o risco de ser citado em qualquer que seja a disciplina específica do curso.

\section{Considerações finais}

Ao se comparar termo a termo, tanto no primeiro momento, quanto no segundo momento é possível identificar que algumas alterações significativas ocorreram na percepção dos estudantes quanto à natureza e essência da disciplina Teoria da Contabilidade, evidenciando certa evolução no entendimento quanto ao tema proposto pelo estudo, principalmente quanto ao quesito nova estrutura conceitual da Contabilidade, uma vez que após o contato dos estudantes com os teóricos que lhes apresentaram novas proposições dentro do arcabouço da Contabilidade, novos entendimentos surgiram no imaginário dos alunos transformando sua forma de pensar a Contabilidade na atualidade.

A primeira alteração diz respeito ao termo 'história', que havia sido evocado primeiro com frequência alta, ao passo que no segundo momento o termo até aparece no Núcleo Central, contudo, com uma frequência bastante reduzida. Em seu lugar apareceu o termo 'postulado', importante na nova estrutura conceitual.

No primeiro momento os estudantes partiram da ideia de que aspectos históricos da Ciência Contábil seriam apresentados na disciplina. Contudo, depois notaram que, embora certos elementos históricos tenham sido trabalhados no decorrer da disciplina, eles não corresponderam ao tema central no palco de discussões. É neste momento que o surgimento do termo 'estrutura' evidencia o enriquecimento intelectual dos estudantes demonstrando que a compreensão da estrutura conceitual da contabilidade é elemento central desta ciência. 
Com respeito ao segundo termo em questão observa-se que ocorreu o oposto em relação à história, visto que no primeiro momento o termo 'conceito' apareceu com frequência $f=9$, ao passo que no segundo momento da pesquisa surgiu com frequência superior. Observa-se que mesmo sutilmente alguma coisa apareceu no imaginário dos estudantes provocando aumento na evocação do termo, corroborando com 0 entendimento anterior de que a disciplina exporia elementos conceituais da Contabilidade.

A princípio o termo 'teoria' foi evocado com frequência $f=9$ e $O M E=1,6$, o que a posiciona em evidência no Núcleo Central por apresentar OME adequada. Por outro lado, no segundo momento, mesmo o termo aparecendo no Núcleo Central, perdeu um pouco da importância, constatação evidenciada a partir da diminuição da frequência e aumento da OME. Esta queda no termo 'teoria' aconteceu pelo fato de que para os alunos 'postulado' e 'estrutura' assumem após os estudos um lugar bastante consolidado dentro da disciplina, um indício da influencia dos artigos de ludícibus, Buchweitz (2009), Madeira (2003) e da resolução do CFC n. 1.282/10 tratando da nova estrutura conceitual da Contabilidade, que por sua vez alterou a resolução n. 750/93.

Partindo para Primeira Periferia observou-se que, no primeiro momento, os termos com alta frequência de evocação situavam-se no Núcleo Central, ao passo que no segundo momento os termos com alta frequência deslocaram-se para a Primeira Periferia. Com frequência $f=9$ o termo 'início' apareceu em primeiro lugar. Já no segundo momento o termo que se destaca é 'princípio': $f=21$. Contudo, cabe ressaltar que estes dois termos são intercambiáveis, ou seja, podem ser usados com o mesmo propósito.

Em segundo lugar apareceu o termo 'estudo'. Na segunda fase da pesquisa este termo desceu para Segunda Periferia reduzindo consideravelmente a frequência de evocação. O termo que ocupou o segundo posto na segunda fase foi 'norma'. Este termo não havia sido evocado no primeiro momento em nenhum dos quadrantes, contudo, surgiu com frequência $f=11$. Em seguida surgiu o termo 'base'. Na segunda fase o termo sobe a frequência de evocação e estabiliza a OME.

Os resultados obtidos permitem-nos concluir que o aumento vertiginoso da frequência de evocação neste quadrante reforçou algumas convicções dos estudantes, contudo, a alta OME não permite deslocar estes termos para o Núcleo Central.

Com respeito à Segunda Periferia nos limitamos a comentar certos termos que se julgou convenientes para análise. Primeiro deles é 'leitura', com frequência $f=3$ na primeira fase da pesquisa. Na segunda fase o termo permaneceu com a mesma frequência alterando a OME. Em segundo lugar o termo 'essência' proporcionou leve alteração em sua frequência visto que no primeiro momento apresentou frequência $f=2$ e no segundo momento $f=3$. Finalmente o termo 'ativo', que no primeiro e segundo momento da pesquisa permaneceu com a mesma frequência modificando-se, porém, a OME.

Partindo do entendimento de que a segunda periferia é um retrato do pensamento heterogêneo do grupo alvo da pesquisa, todas estas mudanças de entendimento são completamente justificáveis vista se tratar do quadrante mais volátil da matriz.

$\mathrm{Na}$ Zona de Contraste, dos termos citados no primeiro momento - ensino, pesquisa, texto - nenhum deles foram evocados no segundo momento. Já os termos evocados na segunda fase da pesquisa foram: fundamento, conhecimento, patrimônio, distorção e alicerce. 
Os dados coletados permitem-nos concluir que a percepção inicial evidenciada na primeira fase da pesquisa não se confirma no segundo momento porque naquele primeiro momento a visão dos estudantes ainda não havia se formado com clareza, fato confirmado pelos resultados obtidos na Zona de Contraste da segunda fase da pesquisa e pela ausência de leitura dos teóricos da disciplina, realidade ocorrendo apenas no decorrer das aulas.

Tomando como base tais resultados da análise em que os estudantes não possuem conhecimento suficiente para esboçar visão equilibrada sobre certas disciplinas do curso de Ciências Contábeis, o estudo permite-nos sugerir que a disciplina seja ofertada nos semestres finais do curso, tendo em vista que os conteúdos apresentados seriam melhor abstraídos pelos estudantes a partir dos conhecimentos teóricos desenvolvidos ao longo do curso.

\section{Referências}

ABRIC, Jean-Claude. Prácticas sociales y representaciones. México: Presses Universitaires de France, 2001.

AMARAL, Liliane Souza do; ALVES, Mariana Silva. Nó ou núcleo central e esquema periférico. Cadernos CESPUC, Belo Horizonte, v. 23, 2013, p. 13-18.

BAILER, Cyntia; TOMITCH, Lêda Maria Braga; D’ELY, Raquel Carolina Souza Ferraz. O planejamento como processo dinâmico: a importância do estudo piloto para uma pesquisa experimental em linguística aplicada. Intercâmbio, São Paulo, v. 24, 2011, p. 129-146.

BORBA, José Alonso; POETA, Fabiana Zandonai; VICENTE, Ernesto Fernando Rodrigues. Teoria da contabilidade: uma análise da disciplina nos programas de mestrado brasileiros. Sociedade, Contabilidade e Gestão, Rio de Janeiro, v. 6, n. 2, 2011, p. 124138.

BUCHWEITZ, Michele Josiane Rutz; PEREIRA, Thaís Aparecida; CRUZ, Ana Paula Capuano da; BARBOSA, Marco Aurélio Gomes. Além de Watts e Zimmerman: a precursão da teoria positiva da contabilidade nos estudos de dumarchey e a influência dos autores na literatura contábil permanente. Sinergia - Revista do Instituto de Ciências Econômicas, Administrativas e Contábeis, Rio Grande, v. 23, n. 1, 2019, p. 9-18.

CFC. Resolução do Conselho Federal de Contabilidade (CFC) n. 1.121/08. Brasilia: CFC, 2008.

CFE. Resolução 03/92: estabelece o currículo pleno do curso de Ciências Contábeis no Brasil. Brasilia: DOU, 1992.

CORREIA, José Carlos; JOIA, Luiz Antonio. A representação social das competências essenciais aos Cios sob a perspectiva dos profissionais de TI. EnANPAD, 38, 2014. Anais ... Rio de Janeiro: Anped, 2014.

COUTINHO, Maria da Penha de Lima; BÚ, Emerson do. A técnica de associação livre de palavras sobre o prisma do software Tri-deux (version 5.2). Revista Campo do Saber, Cabedelo, v. 3, 2017, p. 219-243.

CUNHA, Leila Chaves; BORGERT, Altair; SOUZA, Flávia Renata de; RICHARTZ, Fernando. A disciplina Teoria da Contabilidade em cursos de graduação: percepção de alunos e professores. Revista Gestão Universitária na América Latina, Florianópolis, v. 10, n. 3, 2017, p. 182-203. 
FRANCO, Hilário. Da importância dos princípios fundamentais de contabilidade na harmonização das normas e informações contábeis. Revista Brasileira de Contabilidade, Brasília, v. 24, n. 95, 1995, p. 36-46.

IUDíCIBUS, Sérgio de. Teoria da contabilidade: evolução e tendências. Revista de Contabilidade do Mestrado em Ciências Contábeis da Uerj, Rio de Janeiro, v. 17, n. 2, 2012, p. 5-13.

IUDÍCIBUS, Sérgio de; MARION, José Carlos; FARIA, Ana Cristina de. Introdução à teoria da contabilidade. São Paulo: Atlas, 2009.

IUDíCIBUS, Sérgio de; MARTINS, Eliseu; GELBCKE, Ernesto Rubens. Manual de contabilidade das sociedades por ações: aplicável às demais sociedades. São Paulo: Atlas, 2000.

IUDÍCIBUS, Ségio de; BEUREN, Ilse Maria; SANTOS, Vanderlei dos. Teaching of accounting theory in accounting sciences postgraduate programs in Brasil. Revista Universo Contábil, Blumenau, v. 2016, n. 4, 2016, p. 6-29.

MADEIRA, Geová José; MENDONÇA, Kênia Fabiana Cota; ABREU, Simone Martins. A disciplina teoria da contabilidade nos exames de suficiência e provão. Contabilidade Vista \& Revista, Belo Horizonte, v. 14, 2003, p. 103-122.

MOSCOVICI, Serge. A representação social da psicanálise. Rio de Janeiro: Zahar, 1978.

PAGANOTTO, Juliane Fank; ROSSONI, Estela Pitwak; FILHO, José Francisco Ribeiro. Uma investigação sobre o nível de conhecimento e observância da aplicação dos princípios fundamentais de contabilidade em escritórios de contabilidade. Revista de Educação e Pesquisa em Contabilidade (REPeC), Brasília, v. 1, n. 2, 2007, p. 94-110.

SACRAMENTO, Célia Oliveira de Jesus. O ensino de teoria da contabilidade no Brasil. Caderno de Estudos Fipecafi, São Paulo, v. 10, n. 18, 19998, p. 1-10.

SANTOS, José Victor de Oliveira; ARAÚJO, Ludgleydson Fernandes de; CASTRO, Jerffeson Luiz de Cerqueira; FARO, André. Análise prototípica das representações sociais sobre as infecções sexualmente transmissíveis entre adolescentes. Psicogente, Barranquilla, v. 22, n. 41, 2019, p. 1-18.

SILVA, Maurício Corrêa da; NASCIMENTO, João Carlos Hipólito Bernardes do; SILVA, José Dionísio Gomes da; SIQUEIRA, José Ricardo Maia de. Uma abordagem sobre a aplicação da teoria da resposta ao item nas avaliações de aprendizagem do ensino contábil brasileiro. Cuadernos de Contabilidad, Colombia, v. 20, n. 50, 2019, p. 1-21.

SILVA, Sílvio Éder Dias da; CAMARGO, Brigido Vizeu; PADILHA, Maria Itayra. A teoria das representações sociais nas pesquisas da enfermagem brasileira. Revista Brasileira de Enfermagem, Brasília, v. 64, n. 5, 2011, p. 947-951.

TAVARES, Derek Warwick da Silva; BRITO, Raissa Carneiro de; CÓRDULA, Ana Cláudia Cruz; SILVA, Julianne Teixeira e; NEVES, Dulce Amélia de Brito. Protocolo verbal e teste de associação livre de palavras: perspectivas de instrumentos de pesquisa introspectiva e projetiva na ciência da informação. Ponto de Acesso, Salvador, v. 8, 2014, p. 64-79.

TEIXEIRA, Enise Barth. A Análise de dados na pesquisa científica importância e desafios em estudos organizacionais. Desenvolvimento em Questão, ljuí, v. 1, n. 2, 2003, p. 177201.

VERGARA, Sylvia Constant. Projetos e relatórios de pesquisa em administração. São Paulo: Atlas, 2016. 
WACHELKE, João; WOLTER, Rafael. Critérios de construção e relato da análise prototípica para representações sociais. Psicologia: Teoria e Pesquisa, Brasília, v. 27, n. 4, 2011, p. 521-526.

WACHELKE, João; WOLTER, Rafael; MATOS, Fabíola Rodrigues. Efeito do tamanho da amostra na análise de evocações para representações sociais. Liberabit, Lima, v. 22, n. 2, 2016, p. 153-160.

YAMAKAWA, Eduardo Kazumi; KUBOTA, Flávio Issao; BEUREN, Fernanda Hansch; SCALVENZI, Lisiane; CAUCHICK MIGUEL, Paulo Augusto. Comparativo dos softwares de gerenciamento de referências bibliográficas: Mendeley, EndNote e Zotero. Transinformação, Campinas, v. 26, n. 2, 2014, p. 167-176.

Valdecir de Sousa Salgueiro Filho é professor de Geografia na Escola Municipal Tomé de Sousa de Imperatriz/MA.

Orcid: https://orcid.org/0000-0002-7076-9347.

Endereço: Rua Urbano Santos, s/n - 65900-410 - Imperatriz - MA - Brasil.

E-mail: filhosalgueiro@gmail.com.

Pablo Francisco Sousa Carvalho é estudante de Ciências Contábeis na Universidade Federal do Maranhão.

Orcid: https://orcid.org/0000-0002-7146-9610.

Endereço: Rua Urbano Santos, s/n - 65900-410 - Imperatriz - MA - Brasil.

E-mail: pablofsc97@gmail.com.

Isael Mendes de Sousa é bacharel em Ciências Contábeis.

Orcid: https://orcid.org/0000-0002-1502-2347.

Endereço: Rua Pará, 873 - 65901-580 - Imperatriz - MA - Brasil.

E-mail: isaelmd@gmail.com.

Cleber Augusto Pereira é professor adjunto de Ciências Contábeis na Universidade Federal do Maranhão, campus de Imperatriz.

Orcid: http://orcid.org/0000-0002-7704-2343.

Endereço: Rua Urbano Santos, s/n - 65900-410 - Imperatriz - MA - Brasil.

E-mail: kcleber@gmail.com.

Recebido em 26 de maio de 2020.

Aceito em 14 de setembro de 2020. 